\title{
Overexpression of recombinant domain III envelope protein of Zika virus
}

\author{
Sylvia Empiang Andrew, Easther Manye Kennedy and Magdline Sia Henry Sum
}

Institute of Health and Community Medicine, Universiti Malaysia Sarawak, 94300 Kota Samarahan

Email: shsmag@unimas.my

\begin{abstract}
Aims: Zika virus (ZIKV) is a member of the Flaviviridae family and is transmitted to humans by mosquitoes. In humans, it causes disease known as Zika fever. The severity of the infection ranged from asymptomatic to mild disease and to infection associated with neurological disorders and congenital anomaly. The common symptoms are maculopapular rash, fever, arthralgia, myalgia, headache and conjunctivitis. The flavivirus genome consists of structural and nonstructural proteins. The envelope (E) glycoprotein is the major structural protein which is responsible for virus entry and represents a major target for neutralizing antibodies. The E protein consists of three distinct domains: domain I, domain II and domain III. The domain III (DIII) of the E protein has shown to be useful as antigen for flavivirus serologic diagnosis and immunization in animal model. Hence, the aim of this work is to express the DIII of E protein (EDIII) of ZIKV for immunoreactivity study.

Methodology and results: The EDIII of ZIKV was cloned into pET SUMO cloning vector and transformed into Mach-T1 competent $E$. coli cells. Positive clone was selected, verified and transformed into BL21 (DE3) competent E. coli for protein expression. The expression of the recombinant protein was analysed on SDS-PAGE and western blot. The recombinant fusion protein of EDIII/SUMOHIS (rEDIII) was successfully expressed at a molecular weight of approximately $38.2 \mathrm{kDa}$.
\end{abstract}

Conclusion, significance and impact of study: The expression of the protein was confirmed by detection with antihistidine and a flavivirus antiserum, HPR.

Keywords: Recombinant protein, domain III, Zika virus

\section{INTRODUCTION}

Zika virus (ZIKV) is a member of the Flaviviridae family and is transmitted to humans by mosquitoes (Alera et al., 2015). Originating from Africa, the virus was first isolated in the 1970s and until several years ago was only endemic in Africa and Asia (Hayes, 2009). Recently, large outbreaks were reported outside Africa and Asia that include the outbreak in Micronesia, on the island of Yap in 2007 (Duffy et al., 2009) and in the southern and western Pacific region including French Polynesia, New Caledonia, Easter Island and Cook Island at the end of 2013 and early 2014 (Musso et al., 2014) and the most recent in Brazil in April 2015 (Zanluca et al., 2015). In several non-endemic countries including Japan, Germany, Italy, Canada, Australia and the United States, the infection has been diagnosed in returning travelers (Zammarchi et al., 2015). Although considered a relatively mild disease, its disease spectrum is currently not well understood. For example, during the outbreak in French Polynesia in 2013, infection with ZIKV was associated with increased incidence of neurological complications including a 20 -fold increase of Guillain-Barré syndrome that warrants further studies (Oehler et al., 2014).
In Asia, Zika fever has been described sporadically in the Philippines (Alera et al., 2015), Cambodia (Heang et al., 2012), Thailand (Buathong et al., 2015) and Indonesia (Olson et al., 1990). Although it had been reported that antibodies against ZIKV were demonstrated in serum samples from patients in peninsular and Borneo in the 50s and 60s (Smithburn, 1969), there is no recent report of Zika fever in Malaysia. However, in May of this year Tappe and colleagues (2015) had reported an acute ZIKV infection in a traveler returning from Borneo, Sabah. Thus, in Borneo, either the virus only rarely infects humans or there is a possibility that the disease is mistaken to other closely related diseases such as dengue and chikungunya. Given that the clinical symptoms of Zika fever are very similar to that of dengue, diagnostic confusion between ZIKV illness and dengue or even chikungunya is possible and has been reported widely (Cook and Holmes, 2006; Caron et al., 2012; Roth et al, 2015).

Due to this, laboratory confirmation of suspected cases is necessary for proper management of the cases. Generally, diagnosis of ZIKV infection is achieved by reverse transcription polymerase chain reaction (RT- 
Malays. J. Microbiol. Vol 14(4) Special Issue 2018, pp. 325-328 DOI: http://dx.doi.org/10.21161/mjm.144185

PCR) and by serological assays that detect the presence of ZIKV-induced antibodies (Musso and Gubler, 2016). However, detection by RT-PCR is only limited during the viremic phase of the infection (Lanciotti et al., 2008) therefore specific serological assays are needed. The interest of this study therefore, is to investigate the application of the envelope (E) protein of ZIKV for the development of a serological assay for detection of ZIKVinduced $\lg M$ and $\lg G$ antibodies. The $E$ protein is the major structural protein with three distinct domains namely domain I, domain II and domain III (Rey et al., 1995). Here, the focus was on cloning and expressing the domain III (DIII) region of the envelope gene of ZIKV. The DIII region of ZIKV envelope gene was amplified using specific primers, designed in this study and was cloned in E. coli cloning vector. Positive transformants was screened by colony PCR and the selected clone was verified by DNA sequencing. The recombinant protein was expressed, and the reactivity of the protein was tested against a flavivirus antiserum, HPR (Cardosa et al., 2002).

\section{MATERIALS AND METHODS}

\section{Viral culture}

ZIKV of the MR766 strain was propagated in Vero cells. Briefly, the Vero cells monolayer were inoculated at 95\% confluency in Dulbecco's Modified Eagle Medium, DMEM (Gibco, NY, USA) supplemented with 3\% heat inactivated foetal bovine serum (FBS), penicillin $\mathrm{G}$ and streptomycin sulphate at $50 \mu \mathrm{g} / \mathrm{ml}$ each. The cell culture supernatant was harvested by centrifugation at $200 \times \mathrm{g}, 4^{\circ} \mathrm{C}, 10 \mathrm{~min}$ (Avanti J-25, Beckman, CA, USA) once cytopathic effect was observed.

\section{Viral RNA extraction and RT-PCR}

Table 1: Primer pair for amplification of the partial envelope gene.

\begin{tabular}{|c|c|c|}
\hline Primers & Sequence & $\begin{array}{l}\text { Nucleotide } \\
\text { position* }^{*}\end{array}$ \\
\hline $\mathrm{ZD} \mathrm{F}_{1}$ & $\begin{array}{l}\text { 5'-ACC TGG GTT GAT GTT } \\
\text { GTC TTG-3' }\end{array}$ & $1031-1052$ \\
\hline ZD3R $_{1}$ & $\begin{array}{l}\text { 5'-CTT TCG CTC TAT TTT } \\
\text { CGT CAG TT-3' }\end{array}$ & $1448-1471$ \\
\hline
\end{tabular}

*with reference to ZIKV full genome sequence, NCBI accession no. LC002520

The ZIKV RNA was extracted using the High Pure Viral Nucleic Acid Kit (Roche, IN, USA) according to the manufacturer's protocol and the RNA was eluted in $50 \mu \mathrm{L}$ of elution buffer. The RT-PCR was performed using the primer pair shown in Table 1. The RT-PCR was done as previously described (Sum and Andrew, 2015). The PCR was performed at $94{ }^{\circ} \mathrm{C}$ for 5 min followed by 35 cycles at $94{ }^{\circ} \mathrm{C}$ for $30 \mathrm{sec}, 55^{\circ} \mathrm{C}$ for $30 \mathrm{sec}$ and $72{ }^{\circ} \mathrm{C}$ for $50 \mathrm{sec}$, with a final extension at $72{ }^{\circ} \mathrm{C}$ for $5 \mathrm{~min}$. The PCR product was analysed on a $1.5 \%$ agarose gel electrophoresis.

\section{Cloning and expression}

Cloning and expression were done using the Champion ${ }^{\mathrm{TM}}$ pET SUMO Expression System as protocol recommended by the manufacturer (Invitrogen, CA, USA). Briefly, the target region was inserted into the TA cloning site of the $\mathrm{pET}$ SUMO vector. The ligated product was transformed into Mach1 competent $E$. coli cells and spread on Luria Bertani agar plate with $50 \mu \mathrm{g} / \mathrm{mL}$ Kanamycin. Colony with the ligated insert were selected using colony PCR and the sequence of the selected clone was verified by DNA sequencing. The recombinant plasmid of the selected clone was purified using Purelink Miniplasmid Preparation (Invitrogen, CA, USA) and transformed into BL21(DE3) competent E. coli cells for protein expression analysis. The protein expression was analysed on SDS-PAGE. For this purpose, an overnight culture in the expression host was diluted to $1 / 10^{\text {th }}$ in growth media and subjected to a $2 \mathrm{~h}$ shaking at $225 \mathrm{rpm}$ in a $37^{\circ} \mathrm{C}$ incubator shaker. Afterwards, IPTG was added to induce the culture to a final concentration of $1 \mathrm{mM}$ and incubated for another $3 \mathrm{~h}$ in the incubator shaker. The cells were harvested by centrifugation at $5,000 \times g, 4^{\circ} \mathrm{C}$, $5 \mathrm{~min}$. The cell pellet was resuspended in reducing sample buffer. The sample was heated at $95{ }^{\circ} \mathrm{C}$ for 10 min prior to loading onto a $12 \%$ SDS-PAGE.

\section{SDS-PAGE and western blot}

The electrophoresis was performed in a vertical direction with a constant voltage of $150 \mathrm{~V}$ in $1 \times$ Tris-glycine running buffer (25mM Tris, $192 \mathrm{mM}$ Glycine, 0.1\% SDS pH 8.3) according to Laemmli (1970). At the end of the run, the gel was either stained with Coomassie Brilliant Blue (CBB) or transferred to a nitrocellulose membrane by western blotting according to Towbin et al. (1979). For this purpose, the gel was overlaid with nitrocellulose membranes in a cassette of filter papers and sponges on both sides then the whole cassette was put into a chamber containing Towbin buffer (25 mM Tris, $192 \mathrm{mM}$ glycine, $20 \% \mathrm{v} / \mathrm{v}$ methanol). The transfer was run at constant $\mathrm{mA} 200$ for $1 \mathrm{~h}$ at room temperature.

\section{Immunoblotting}

The membranes were blocked for $30 \mathrm{~min}$ at room temperature in either $1 \times$ PBS containing $5 \%$ skimmed milk or in $1 \%$ BSA-PBS for probing with the flavivirus antiserum and antihistidine respectively. The membranes were either probed with HisDetector Nickel HRP (KPL, MD, USA) at 1:500 in blocking buffer for $2 \mathrm{~h}$ or with the flavivirus antiserum, HPR at 1:1000 for an overnight incubation on a rocker at room temperature, followed by anti-human IgG HRP (Dako, Denmark) for $2 \mathrm{~h}$ the following day. Colorimetric substrate (4-chloro-1-napthol in methanol $/ \mathrm{H}_{2} \mathrm{O}_{2}$ ) were added for $30 \mathrm{~min}$ for colour development. Between steps, membranes were subjected to $3 \times$ washes with $1 \times$ PBS at 10 min intervals after each of the incubation. 
Malays. J. Microbiol. Vol 14(4) Special Issue 2018, pp. 325-328 DOI: http://dx.doi.org/10.21161/mjm.144185

\section{RESULTS AND DISCUSSION}

The domain III (DIII) of flavivirus envelope protein contains a panel of important epitopes that are recognized by virus neutralizing monoclonal antibodies making it a suitable candidate as antigens to be used in serologic diagnosis or as targets for immunization for these viruses (Mathengtheng and Burt, 2014).

In this study we had cloned the gene and expressed the protein of the DIII region of ZIKV. The DIII region was amplified using the ZD3F1 and ZD3R1 (Table 1) primer pair. The RT-PCR generated a single band at the expected size of $432 \mathrm{bp}$ (Figure 1) and the nucleotides were confirmed by DNA sequencing. The PCR product was ligated into the pETSUMO vector and successful clone was expressed using prokaryotic system, in E. coli cells. The main advantage of this system is, the ability to expressed desired recombinant protein in large quantities and for that reason this system was used in this study.

Here, the recombinant EDIII (rEDIII) protein was expressed as a fusion protein with the $11 \mathrm{kDa}$ SUMO moiety and $6 \times$ hisitidine tag at the $\mathrm{N}$-terminal. The presence of the SUMO moiety helps to enhance the solubility of the protein (Malakhov et al., 2004), while the poly-histidine aids in the protein detection and purification. To ensure that growth and induction was performed properly, the system's positive control, pET SUMO/CAT of approximately $39 \mathrm{kDa}$ was expressed alongside the rEDIII protein. Based on the molecular weight, the expected size of the rEDIII fusion protein is approximately $38.2 \mathrm{kDa}$. The overexpression of the rEDIII fusion protein at the correct size was clearly achieved in the induced culture as observed in Figure 2A below.

To confirm that the overexpressed band is the desired protein, western blot was performed, and the blots were tested against Nickel HRP to detect the poly-hisitidine tag and a flavivirus antiserum for detection of the rEDIII protein. Our result shows that both the rEDIII and the control PET SUMO /CAT proteins were clearly detected by the Nickel HRP (Figure 2B) which confirm the expression of the desired proteins. Another blot was tested against HPR, a flavivirus antiserum and the result shows that the rEDIII protein was reactive against the antiserum as the band at the correct size was observed with the induced culture of rEDIII and not with the SUMO/CAT protein (Figure 2C). Although the reaction was faint, because the antiserum is against the whole virus and the domain III region is only a small portion of it, it confirmed that the rEDIII protein is reactive.

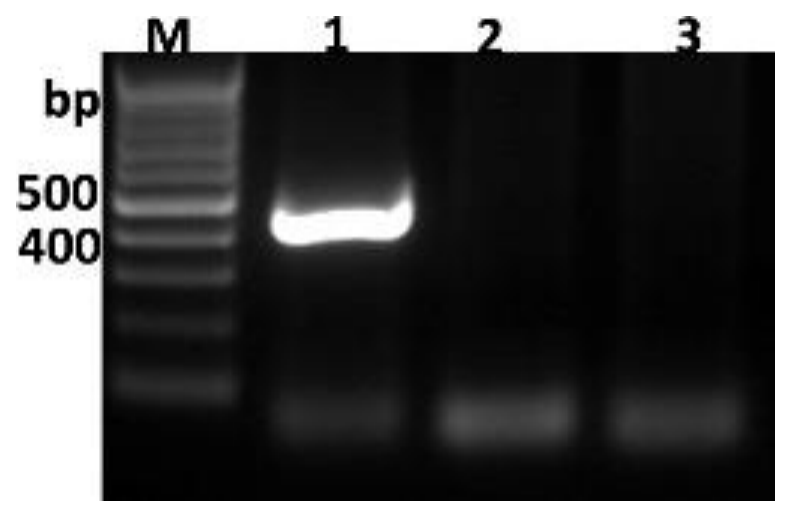

Figure. 1: PCR amplification of target region, EDIII of ZIKV. M: 100 bp DNA ladder (MBI, Fermentas), lane 1: EDIII of ZIKV (432 bp), lane 2: cell control, lane 3: water control.

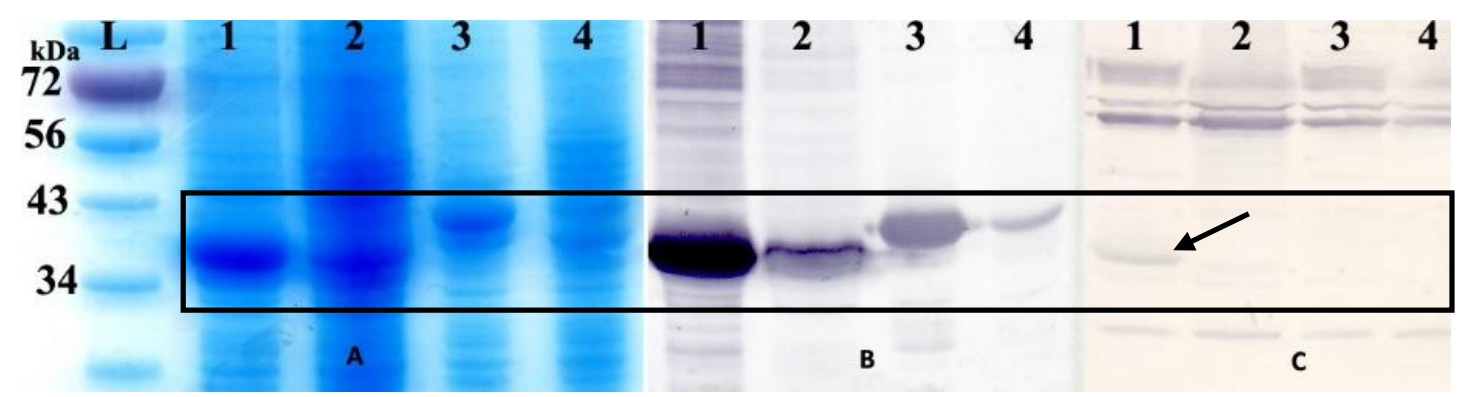

Figure 2: Expression of rEDIII fusion protein. L: EZ-Run protein ladder (Thermo Fisher Scientific), 1: Induced rEDIII fusion protein, 2: Non-induced rEDIII fusion protein, 3: Induced SUMO/CAT control fusion protein, 4: Non-induced SUMO/CAT control fusion protein. Panels (A) CBB stained SDS-PAGE, (B) blot probed with Nickel HRP, (C) blot probed with flavivirus antiserum. 
Malays. J. Microbiol. Vol 14(4) Special Issue 2018, pp. 325-328 DOI: http://dx.doi.org/10.21161/mjm.144185

\section{CONCLUSION}

In conclusion, here we had successfully produced an overexpression rEDIII protein in a relatively short time and in satisfactory quantities. Future work will focus on larger scale induction and purification of the rEDIII as potential antigen for serologic assay. The recombinant antigen will be evaluated in serologic assay for ZIKV detection as well its potential to differentiate infection from other flavivirus.

\section{REFERENCES}

Alera, M. T., Hermann, L., Tac-An, I. A., Klungthong, C., Rutvisuttinunt, W. and Manasatienkij, W. (2015). Zika virus infection Phillipines, 2012. Emerging Infectious Diseases 21(4), 722-724.

Buathong. R., Hermann, L., Thaisomboonsuk, B., Rutvisuttinunt, W. and Klungthong, C. (2015). Detection of Zika virus infection in Thailand, 20122014. American Society Tropical Medicine Hygiene, 93(2), 380-383.

Cardosa, M. J., Wang, S. M., Sum, M. S. H. and Tio, P. K. (2002). Antibodies against prM protein distinguish between previous infection with dengue and Japanese encephalitis viruses. BMC Microbiology 2(9), 1-6.

Caron, M., Paupy, C., Gerrard, G., Becquart, P. and Mombo, I. (2012). Recent introduction and rapid dissemination of chikungunya virus and dengue virus serotype 2 associated with human and mosquito coinfcetions in Gabon, Central Africa. Clinical Infectious Diseases 55(6), e45-e53.

Cook, S. and Holmes, E. C. (2006). A multigene analysis of the phylogenetic relationships among the flaviviruses and the evolution of vector transmission. Archives of Virology 151(2), 309-325.

Duffy, M. R., Chen, T. H., Hancock, W. T., Powers, A. M., Kool, J. L. and Lanciotti, R. S. (2009). Zika virus outbreak on Yap island, federated states of Micronesia. New England Journal of Medicine 360(24), 2536-2543.

Hayes, E. B. (2009). Zika virus outside Africa. Emerging Infectious Diseases 15(9), 1347-1350.

Heang, V., Yasuda, C. Y., Sovann, L., Haddow, A. D., Travassos da Rosa, A. P., Tesh, R. B. and Kasper, M. R. (2012). Zika virus infection, Cambodia, 2010. Emerging Infectious Disease 18(2), 349-351.

Laemmli, U. K. (1970). Cleavage of structural proteins during the assembly of the head of bacteriophage T4. Nature 227, 680-685.

Lanciotti, R. S., Kosoy, O. L., Laven, J. J., Velez, J. O., Lambert, A. J., Johnson, A. J., Stanfield, S. and Duffy, M. R. (2008). Genetic and serologic properties of Zika Virus associated with an epidemic, Yap State, Micronesia, 2007. Emerging Infectious Diseases 14(8), 1232-1239.

Malakhov, M. P., Mattern, M. R., Malakhova, O. A., Drinker, M., Weeks, S. D. and Butt, T. R. (2004). SUMO fusions and SUMO-specific protease for efficient expression and purification of proteins.
Journal of Structural Functional Genomics 5(1-2), 7586.

Mathengtheng, L. and Burt, F. J. (2014). Use of envelope domain III protein for detection and differentiation of Flaviviruses in the free state province, South Africa. Vector-Borne and Zoonotic Diseases 14(4), 261-271.

Musso, D., Nilles, E. J. and Cao-Lormeau, V. M. (2014). Rapid spread of emerging Zika virus in the Pacific area. Clinical Microbiology and Infectious Diseases 20(10), 596-596.

Musso, D. and Gubler, D. J. (2016). Zika Virus. Clinical Microbiology Reviews 29(3), 487-524.

Oehler, E., Watrin, L., Larre, P., Leparc-Goffart, I., Lastere, S. and Valour, F. (2014). Zika virus infection complicated by Guillan Barre syndrome-case report, French Polynesia, December 2013. Eurosurveillance 19(9), 1-3.

Olson, J. G., Ksiazek, T. G. Suhandiman, and Triwibowo. (1990). Zika virus, a cause of fever in Central Java, Indonesia. Transactions of the Royal Society of Tropical Medicine Hygiene 75(3), 389-393.

Rey, F. A., Heinz, F. X., Mandl, C., Kunz, C. and Harrison, S. C. (1995). The envelope glycoprotein from tick-borne encephalitis virus at $2 \AA$ resolution. Nature 375, 291-298.

Roth, A., Mercier, A., Lepers, C., Hoy, D. and Duituturaga, S. (2015). Concurrent outbreaks of dengue, chikungunya and Zika virus infections-an unprecedented epidemic wave of mosquito-borne viruses in the Pacific 2012-2014. Eurosurveillance 19(41), 1-8.

Smithburn, K. C. (1969). Neutralizing antibodies against arthropod-borne viruses in sera of long-time residents of Malaya and Borneo. American Journal of Tropical Medicine Hygiene 59(2), 157-163.

Sum, M. S. H. and Andrew, A. (2015). Expression and evaluation of a $24-\mathrm{kDa}$ recombinant protein of the $\mathrm{N}$ terminal E2 glycoprotein of chikungunya virus. BioTechnology: An Indian Journal 11(3), 109-114.

Tappe, D., Nachtigall, S., Kapaun, A., Schnitzler, P., Gunther, S. and Schmidt-Chanasit, J. (2015). Acute Zika virus infection after travel to Malaysian Borneo, September 2014. Emerging Infectious Diseases 21(5), 911-912.

Towbin, H., Staehelin, T. and Gordon, J. (1979). Electrophoretic transfer of proteins from polyacrylamide gels to nitrocellulose sheets: Procedure and some applications. Proceedings of the National Academy of Sciences USA 76(9), 4350-4354.

Zanluca, C., Campos, V., de Melo, A., Mosimann, A. L. P. and dos Santos, G. I. V. (2015). First report of autochthonous transmission of Zika virus in Brazil. Memorias do Instituto Oswaldo Cruz Journal 110(4), 569-572.

Zammarchi, L., Stella, G., Mantella, A., Bartolozzi, D., Tappe, D. and Gunther, S. (2015). Zika virus infections imported to Italy: Clinical, immunological and virological findings and public health implications. Journal Clinical Virology 63(32), 32-35. 